DOI 10.37882/2223-2974.2021.02.23

\title{
ПРОБЛЕМЫ ИННОВАЦИОННОГО РАЗВИТИЯ РОССИЙСКОЙ ЭКОНОМИКИ
}

\section{PROBLEMS OF INNOVATIVE DEVELOPMENT OF THE RUSSIAN ECONOMY}

\section{N. Trishkina}

T. Goremykina

Summary: At the present stage, the innovative activity of Russian organizations and enterprises is still low. Moreover, in foreign practice, much attention is paid to innovation. Foreign enterprises allocate large sums to the innovation sphere. In this regard, Russian companies are still significantly behind. According to Rosstat, the share of innovatively active business entities in Russia does not exceed $8.5 \%$. This is a critically low rate. In the European Union, this indicator reaches $53 \%$. Another serious problem is the low intensity of innovation costs in the high-tech sector. In our country, the indicator of the intensity of such costs is only $1.9 \%$ (for example, in Germany - 4.7\%). This indicates the high relevance of the study of the problem of innovative development of the economic sector of the Russian Federation.

Keywords: innovative activity, innovations, Russian economy, development, rating, high-tech sector. тришкина Надежда Антоновна

К.э.н., Московский международный университет ntrishkina@list.ru

Горемыкина Татьяна Константиновна К.э.н., Московский международный университет 5149611@mail.ru

Аннотация: На современном этапе инновационная активность российских организаций и предприятий по-прежнему невысока. При этом в иностранной практике инновациям уделяется большое внимание. Иностранные предприятия выделяют большие суммы на инновационную сферу. В этом плане российские компании пока еще существенно отстают. Согласно данным Росстата, доля инновационно-активных бизнес-субъектов в России не превышает 8,5\%. Это критически низкий показатель. В Европейском Союзе данный показатель достигает 53\%. Еще одна серьезная проблема заключается в низкой интенсивности затрат на инновации в высокотехнологичном секторе. В нашей стране показатель интенсивности таких затрат составляет всего 1,9\% (например, в ФРГ - 4,7\%). Это свидетельствует о высокой актуальности проработки проблемы инновационного развития экономического сектора РФ.

Ключевые слова: инновационная активность, инновации, российская экономика, развитие, рейтинг, высокотехнологичный сектор.

тренных инерционным сценарием.

Чтобы разобраться в современной ситуации, рассмотрим основные тенденции инновационного развития России за ряд последних лет в таких областях как наука, образование, кадровый потенциал и др.

На наш взгляд, неопределенность инновационного развития России, связанная, прежде всего с экспортом традиционных энергоносителей, обуславливается появлением в мире экономически эффективных технологий добычи углеводородов из нетрадиционных источников (сланцы, нефтеносные пески и т.д.), что неблагоприятным образом отражается на их спросе и ценах.[4]

Сложившаяся ситуация, во многом неблагоприятная для Россия, может быть решена путем повышения доли высокотехнологичного производства в ВВП секторе, таких как: авиастроение, судостроение, космическая отрасль, электронная промышленность и др., однако, перспектива развития в целях улучшения ситуации сводится, прежде всего к бюджетной поддержке вышеназванных секторов экономики.

Не менее важным моментом является повышение 
глобальной конкурентоспособности инновационных мировых систем за высококвалифицированную рабочую силу.

Одна из общемировых тенденций инновационного развития заключается в последовательном формировании элементов инновационной экономики, среди которых важнейшим значением обладает человеческий капитал. Для построения инновационной экономики необходим не только материальный капитал, но и человеческий. Его уникальность обусловливается тем, что способности и качества индивидов (творчество, креативность и пр.) обладают высокой ценностью в сфере труда и досуга, как для потребительского рынка, так и для рынка труда.

И, хотя проблема человеческого капитала, в нашей стране по-прежнему остается одним из важнейших конкурентных преимуществ, что, возможно, объясняется значительным (более 20\%) охватом численности занятых в экономике базовым образованием, нельзя не учитывать возможное «вымывание» сохраняющегося конкурентоспособного потенциала - кадров, технологий, идей, капитала. [4]

Проблема научных кадров, по-прежнему характеризуется неспособностью многих исследовательских организаций удержать молодых специалистов, также наблюдается незначительное увеличение возрастного уровня научного потенциала 30-39 лет, что осложняет ситуацию по преодолению разрыва поколений, сформировавшегося в российской науке.

Нельзя обойти вниманием такие мировые проблемы как изменение климата, старение населения, здравоохранение, продовольственная безопасность в глобальном масштабе, что требует развития, а, следовательно, и вливания капитала в специфичные направления научных исследований и технологических разработок («чистая» энергетика, геномная медицина, новые технологии в сельском хозяйстве и т.д.).

Оценивая состояние развития инновационных технологий в России, следует отметить тенденцию инерционного импортоориентирования, направленную на поддержание макроэкономической стабильности и низких параметров бюджетных расходов на науку, что может привести к дальнейшему ослаблению национальной инновационной системы, усилению зависимости экономики от иностранных технологий [2].

Сравнивая финансирование науки с развитыми странами, можно отметить, что инновационная сфера в России финансируется в недостаточном объеме, всего 0,56\% ВВП. Рассматривая возможность финансирования инновационного развития путем привлечения иностранного капитала, нельзя не учитывать проблему финансовой зависимости страны, усиление внешних рисков, а также замедление развития собственных разработок.

Однако, следует также отметить, что государственные средства, выделяемые на научно-исследовательские и опытно-конструкторские работы, в большинстве секторов экономики расходуются недостаточно эффективно.

Недостаточный уровень инновационной активности усугублялся низкой отдачей от реализации технологических инноваций. На протяжении ряда лет уровень затрат на рубль инновационной продукции снижался, так же как и макроэкономический показатель объема расходов на исследования и разработки в расчете на душу населения в России, хотя за последние годы удалось сократить его разрыв от высокоразвитых стран.

Одной из основных причин неуспешного развития инновационных программ можно отметить низкий в целом спрос на инновации, а также, как было отмечено, закупка готового оборудования за рубежом в ущерб внедрению собственных новых разработок. [4]

Представим более развернутую информацию, основанную на статистических данных.

В период с 2017 по 2019 годы Россия занимала 43-44 место по субиндексу инновационных ресурсов. Но по результатам внедрения новаций Россия находится только на девятом месте [4, с.13].

Инновационный рейтинг Bloomberg Innovation Index 2019 [5] представлен в табл. 1.

Лидером в инновационном рейтинге Bloomberg за 2019 год является Южная Корея. Она признана страной с самой инновационной экономикой.

Связано это, прежде всего, с повышением интенсивности научно-исследовательских и опытно-конструкторских разработок, а также с выпуском продукции, обладающей высокой добавленной стоимостью. Российская Федерация в этом рейтинге занимает только 27 позицию (между такими странами, как Люксембург и Малайзия). В сравнении с 2018 г. Россия спустилась в рейтинге на две позиции, а по сравнению с 2016 г. - на 15 позиций. Наиболее сильное падение рейтинга РФ в рейтинге инноваций Bloomberg было зафиксировано в 2017 году. Так, в начале 2017 года Российская Федерация находилась на 26 позиции рейтинга, хотя в 2016 году занимала 12 позицию.

В 2019 году Россия смогла занять довольно высокую позицию в рейтинге. Этому поспособствовал показатель, отражающий долю высшего образования (хотя этот показатель и опустился в сравнении с 2018 годом 
на пять позиций). Наиболее низкий показатель - продуктивность. По этому показателю Россия находится на 51 позиции рейтинга (снижение - на 7 позиций). Продуктивность рассчитывается как величина и трехлетнее изменение ВНП и ВВП на работающего по найму. Самый серьезный провал наблюдался в патентной активности. В настоящее время Российская Федерация находится на 30 месте (падение на 14 позиций).

При среднем уровне развития сектора высоких технологий и изобретательской активности экспорт высокотехнологичной продукции все еще остаётся на невысоком уровне. Из РФ на экспорт поступает только 0,5\% от высокотехнологичной продукции мира (в основном, экспортируются военные технологии). При этом доля высокотехнологичного импорта - более 60\%. На рисунке 1 показана доля занятых в высокотехнологичном секторе в Российской Федерации и в Европейском союзе [2].

В мировом объеме полученных платежей за использование объектов интеллектуальной собственности доля России - 0,2\%. К сравнению, у лидирующих стран эта доля составляет 12\% (Япония) и 36\% (Соединенные Штаты). Основу российского высокотехнологичного экспорта формирует энергетическое оборудование.

Нефтегазовая зависимость российской экономики в последние годы, действительно, значительно снизилась. Невысокий рост экспорта российских инновационных технологий во многом обусловлен отсутствием соответствующего законодательства, а также чрезвычайно высокой энергоемкостью национальной экономики РФ, занимающей по рассматриваемому показателю одно из последних мест [2] (рис. 2).

Вместе с тем, Российская Федерация входит в ТОП-30 стран-лидеров по уровню образования (университетского и школьного), по инвестициям в научно-технический сектор, по числу патентов, уровню развития ИТ-сектора, а также по числу людей, занятых интеллектуальной деятельностью.

Проведенный в 2019 году опрос торгово-промышленных палат показал, что одним из основных факторов, способствующих росту объемов работы с инновационными проектами, является увеличение активности инновационного бизнеса, а также совершенствование информированности как торгово-промышленных палат, так и предпринимателей обо всех сопутствующих элементах данной деятельности: регламентных и административных процедурах, мерах поддержки, институтах и реализуемых ими программах [4, с.16] (рис. 3).

Таким образом, доля высокотехнологичного сектора в экономике повышается. Повышается также и уровень инновационного развития экономики России. Но одно только снижение инвестиционных рисков, не связанное с должным увеличением доступности финансирования, не сможет привести к вышеописанным результатам.

Несмотря на позитивную динамику, инновационная активность в РФ находится на невысоком уровне в срав-

Инновационный рейтинг Bloomberg Innovation Index 2019

\begin{tabular}{|c|c|c|c|c|c|c|c|c|c|}
\hline $\begin{array}{l}\text { Место в } \\
\text { рейтинге } \\
\text { в } 2019 \\
\text { году }\end{array}$ & $\begin{array}{c}\text { Изменение } \\
\text { позиции } \\
\text { относительно } \\
2018 \text { года }\end{array}$ & Экономика & $\begin{array}{c}\text { Интенсивность } \\
\text { исследований } \\
\text { и разработок }\end{array}$ & $\begin{array}{c}\text { Произ- } \\
\text { водство } \\
\text { добавленной } \\
\text { стоимости }\end{array}$ & $\begin{array}{c}\text { Продуктив- } \\
\text { ность }\end{array}$ & $\begin{array}{c}\text { Плотность } \\
\text { высоких } \\
\text { технологий }\end{array}$ & $\begin{array}{c}\text { Эффек- } \\
\text { тивность } \\
\text { высшего } \\
\text { образования }\end{array}$ & $\begin{array}{l}\text { Концентрация } \\
\text { исследований }\end{array}$ & $\begin{array}{l}\text { Патентная } \\
\text { активность }\end{array}$ \\
\hline 1 & 0 & $\begin{array}{l}\text { Южная } \\
\text { Корея }\end{array}$ & 2 & 2 & 18 & 4 & 7 & 7 & 20 \\
\hline 2 & +2 & Германия & 7 & 3 & 24 & 3 & 14 & 11 & 7 \\
\hline 3 & +4 & Финляндия & 9 & 16 & 5 & 13 & 9 & 8 & 5 \\
\hline 4 & +1 & Швейцария & 3 & 4 & 7 & 8 & 13 & 3 & 27 \\
\hline 5 & +5 & Израиль & 1 & 33 & 8 & 5 & 36 & 2 & 4 \\
\hline 27 & -2 & Россия & 33 & 37 & 51 & 25 & 10 & 24 & 30 \\
\hline
\end{tabular}

\section{$34 \%$}

\section{Россия Европейский союз}

Рис. 1. Доля занятых в высокотехнологичном секторе в России и ЕС 
нении с иностранными государствами. Сегодня одной из приоритетных задач выступает задача по созданию условий, при которых инновации будут играть ключевую роль в экономике страны. Это необходимо, поскольку постепенно инновации превращаются в основополагающий фактор, определяющий развитие и конкурентоспособность страны на международной арене.

Потенциал роста ВВП России может достичь к 2025 году 3,6 трлн. рублей только за счет внедрения цифровых технологий, подсчитали эксперты McKinsey. Объем ВВП России за 2018 г., по первым оценкам Росстата, со- ставил в текущих ценах 103,6 трлн. руб. Но его рост замедляется. По оценке председателя Счетной палаты в 2020 г. он не превысит 1\% [1].

По числу занятых в научном секторе Россия занимает третье место (после Соединенных Штатов и Китая). Однако пока еще рано говорить о возможном стремительном росте в данной сфере. В настоящее время Российская Федерация отстает от большинства развитых стран почти по всем показателям, отражающим эффективность использования ресурсов и степень воздействия инновационной и научно-технической деятельности на общество

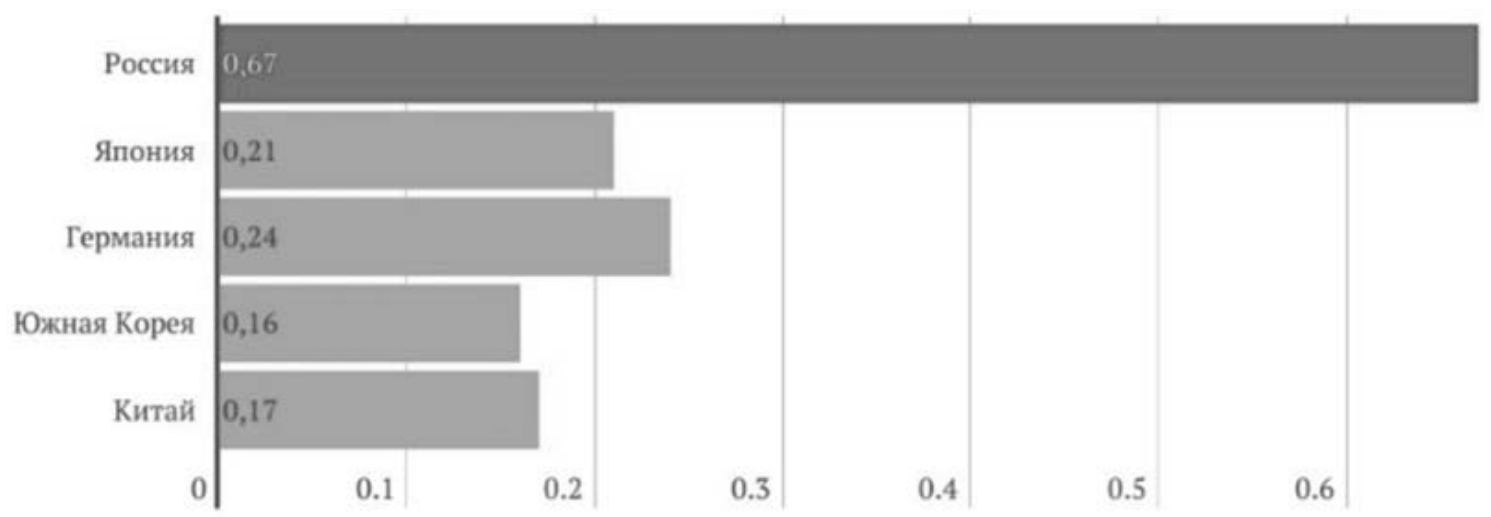

Рис. 2. Зависимость от иностранных технологий (соотношение зарубежных и отечественных заявок на изобретения, 1 - абсолютная импортозависимость, 0 - абсолютная импортонезависимость)

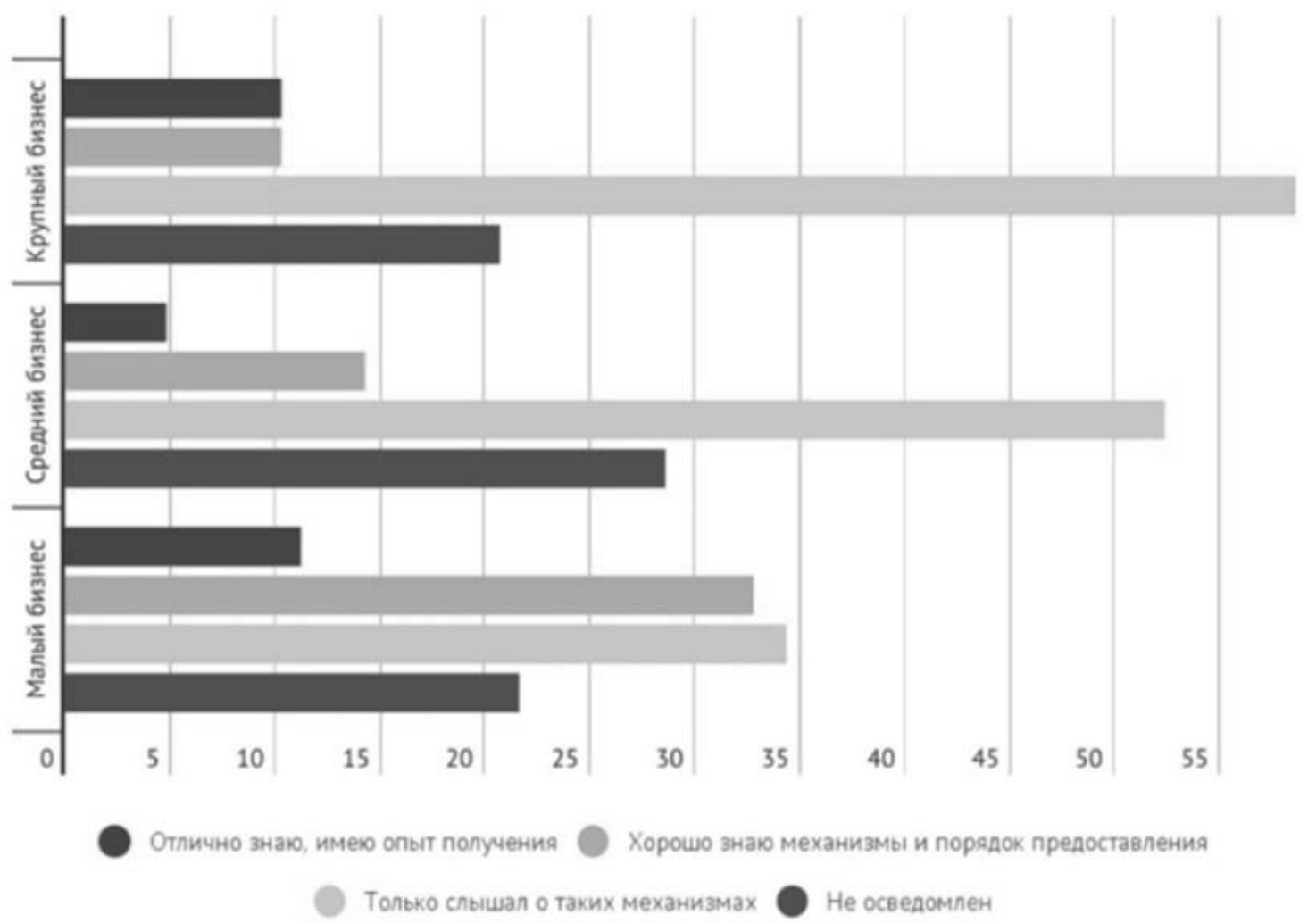

Рис. 3. Масштабы бизнеса и осведомленность о механизмах государственной поддержки инновационной деятельности, \% 
и экономику.

Для исправления сложившейся ситуации разработан национальный проект «Наука», рассчитанный до 2024 года. Бюджет проекта составляет 636 миллиардов рублей. Ключевые направления проекта:

- развитие кадрового потенциала (бюджет - 70,9 миллиардов рублей);

- развитие научно-производственной и научной кооперации (бюджет - 215 миллиардов рублей);

- развитие инфраструктуры для проведения НИОКР (350 миллиардов рублей).

В результате реализации проекта доля ученых в возрасте до 39 лет должна возрасти с 43,3\% до 50,1\%. Как минимум 250 субъектов крупного бизнеса должно быть вовлечено в создание технологий, услуг и продуктов с участием компаний-участников центров компетенции и научно-образовательных центров национальной технологической инициативы. В период реализации проекта ожидается как минимум 1500 патентных заявок.

На современном этапе российская экономика сталкивается с определенными проблемами и трудностями, которые мешают дальнейшему развитию. Устранению многих проблем может поспособствовать эффективное стратегическое прогнозирование и планирование, а также разработка более четкой экономической стратегии на долгосрочную перспективу. При разработке стратегии экономического развития и определении основных ее направлений необходимо учитывать глобальные преобразования, происходящие в инновационной сфере [3, c. 105].

Анализ сложившейся ситуации позволяет выделить наиболее приоритетные и инновационноемкие направления развития:

Высокие технологии. На современном этапе стратегическими позициями России являются высокие технологии и инновационный путь развития. Приоритетными направлениями выступают: высокие технологии, инновации, агропромышленный комплекс, промышленная политика, качество образования. Важнейшими стратегическими задачами национальной экономики являются приумножение научно-технического потенциала и развитие наукоемкого производства. Все это требует создания информационной экономики и развитой инфраструктуры. Следовательно, создание инновационной инфраструктуры должно стать одним из приоритетных направлений стимулирования и развития инновационной деятельности.

Социально ориентированное направление. Несмотря на важность экономических условий, социальные аспекты также обладают немаловажным значением. Инновационные преобразования приводят к определенным социальным последствиям, недооценка которых может серьезно сказаться на успешности таких преобразований. Не стоит забывать, что главный ресурс инновационных преобразований - человек и его знания. В этой связи, в настоящее время наблюдается активное развитие качественно новой социально ориентированной экономики.

Привлечение внимания к социально ориентированному направлению инноваций - характерный признак нынешней парадигмы инновационного развития государства. Российская Федерация взяла курс на реформирование институтов развития человеческого капитала, что позволяет с уверенностью говорить о перспективности данного направления развития инновационного сектора.

Одна из общемировых тенденций инновационного развития заключается в последовательном формировании элементов инновационной экономики, среди которых важнейшим значением обладает человеческий капитал. Для построения инновационной экономики необходим не только материальный капитал, но и человеческий. Его уникальность обусловливается тем, что способности и качества индивидов (творчество, креативность и пр.) обладают высокой ценностью в сфере труда и досуга, как для потребительского рынка, так и для рынка труда.

Сервисная экономика. Сфера услуг играет важную роль в мировой экономике и экономике отдельных государств, так как именно в данном секторе формируются ключевые факторы экономического роста (консалтинг; финансовые услуги; информационные технологии; интеллектуальный капитал; новые научные знания). За последние десять лет доля услуг в структуре ВВП существенно возросла. Поэтому необходимо уделить особое внимание развитию конкурентоспособной сервисной экономики.

Россия обладает внушительным рекреационным потенциалом, однако реализации данного потенциала препятствуют определенные проблемы - дефицит квалифицированных специалистов и неразвитость инфраструктуры (гостиничной, транспортной, дорожной и др.). Соответственно, устранение существующих проблем положительно скажется на развитии сервисной экономики.

Таким образом, основываясь на вышесказанном, приходим к выводу о необходимости разработки модели инновационного развития экономики России. Такая модель должна учитывать особенности социально-экономического развития государства и специфику человеческого капитала в целях интегрирования в мировую инновационную систему, уход от сохраняющейся изоляции и сохранения научного потенциала России. 


\section{ЛИТЕРАТУРА}

1. Белкина, А. Как развиваются инновации в России / А. Белкина // Ведомости [Электронный ресурс]. - Режим доступа: https://www.vedomosti.ru/partner/ articles/2019/10/09/813027-razvivayutsya-innovatsii (Дата обращения 16.04.2020)

2. Вялкин, А. С нефтяной иглы на инновационную? / А. Вялкин // Департамент содействия инвестициям и инновациям ТПП РФ [Электронный ресурс]. Режим доступа: https://tpprfrru/ru/interaction/experts/comments/343081 (Дата обращения 16.04.2020)

3. Ишмухаметов Н.С. Теоретические проблемы исследования инновационной экономики / Н.С. Ишмухаметов // Инновационное развитие экономики: тенденции и перспективы. - 2016.- № 1.- С. 103-110

4. Шик, Е.В. Анализ инновационной активности России на основе международного сопоставления / Е.В. Шик, И.В. Шарова // Экономические исследования и разработки. - 2019.- № 7.- С.12-25.

5. The 2019 Bloomberg Innovation Index. Bloomberg [Электронный ресурс]. - Режим доступа: https://www.bloomberg.com (Дата обращения 16.04.2020)

( Тришкина Надежда Антоновна (ntrishkina@list.ru), Горемыкина Татьяна Константиновна (5149611@mail.ru).

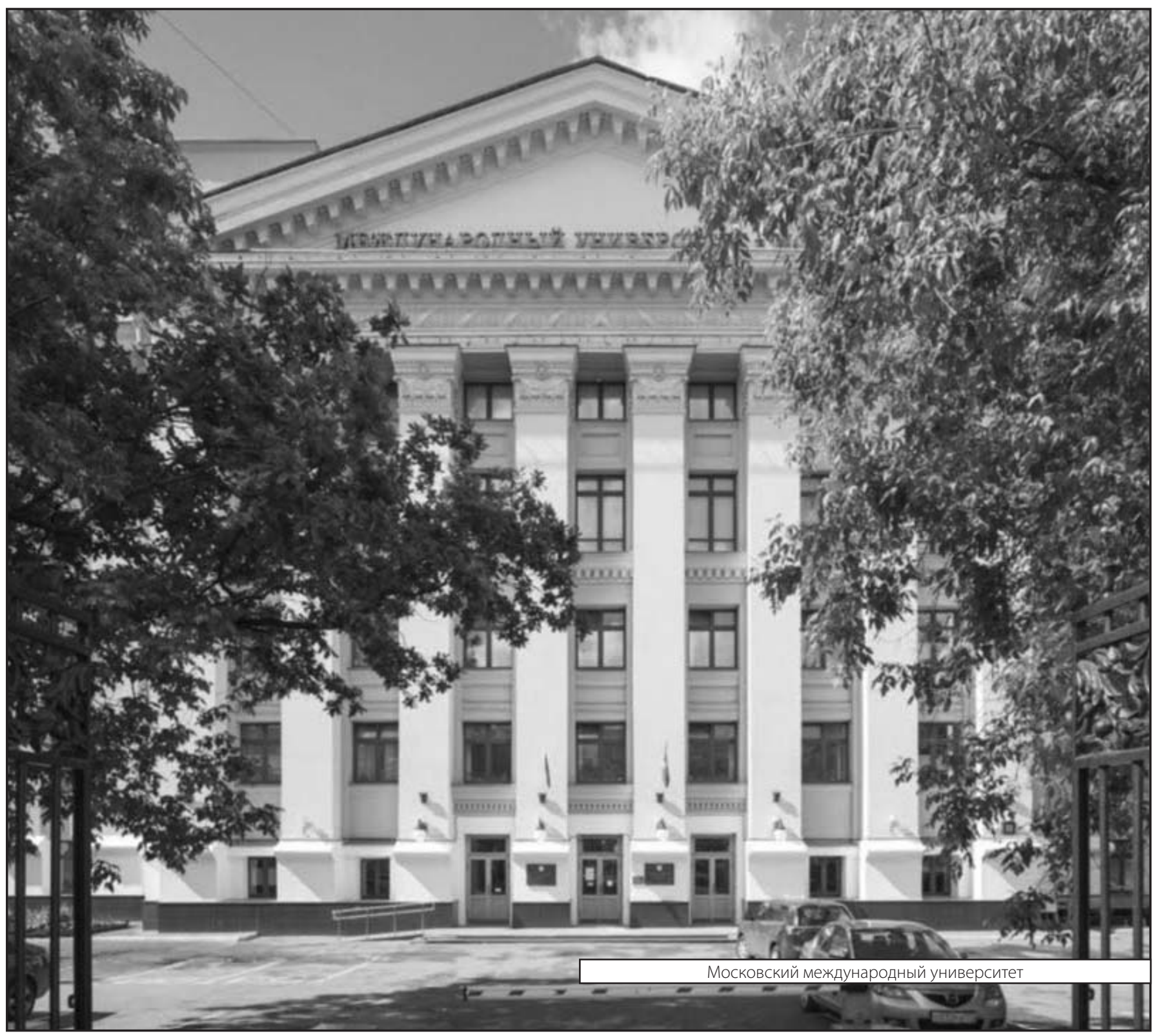

